\title{
GRPR/PI3K $\gamma:$ Partners in Central Transmission of Itch
}

\author{
Paula J.S. Pereira, ${ }^{1,3,6}$ Gustavo D.B. Machado, ${ }^{2,3 \star}$ Giuliano M. Danesi, ${ }^{2,3 *}$ Francesca F. Canevese, ${ }^{2,3}$ Vemuri B. Reddy, ${ }^{6}$ \\ Talita C.B. Pereira, ${ }^{4}$ Maurício R. Bogo, ${ }^{1,3}$ Yung-Chih Cheng, ${ }^{7}$ Cedric Laedermann, ${ }^{7}$ 'Sébastien Talbot, ${ }^{7}$ \\ -Ethan A. Lerner, ${ }^{6}$ and Maria M. Campos ${ }^{3,4,5}$ \\ ${ }^{1}$ Programa de Pós-graduação em Biologia Celular e Molecular, ${ }^{2}$ Faculdade de Medicina e Ciências da Saúde, ${ }^{3}$ Instituto de Toxicologia e Farmacologia, \\ ${ }_{4}^{4}$ Programa de Pós-graduação em Medicina e Ciências da Saúde, and ${ }^{5}$ Faculdade de Odontologia, Pontifícia Universidade Católica do Rio Grande do Sul, \\ 90619-900, Porto Alegre, RS, Brazil, ${ }^{6}$ Cutaneous Biology Research Center, Department of Dermatology, Massachusetts General Hospital and Harvard \\ Medical School, Boston, Massachusetts 02114, and 7F.M. Kirby Neurobiology Center, Children's Hospital Boston, Boston, Massachusetts 02115
}

The gastrin-releasing peptide (GRP) and its receptor (GRPR) are important components of itch transmission. Upstream, but not downstream, aspects of GRPR signaling have been investigated extensively. We hypothesize that GRPR signals in part through the PI3K $\gamma / \mathrm{Akt}$ pathway. We used pharmacological, electrophysiological, and behavioral approaches to further evaluate GRPR downstream signaling pathways. Our data show that GRP directly activates small-size capsaicin-sensitive DRG neurons, an effect that translates into transient calcium flux and membrane depolarization $(\sim 20 \mathrm{mV})$. GRPR activation also induces Akt phosphorylation, a proxy for PI3K $\gamma$ activity, in ex vivo naive mouse spinal cords and in GRPR transiently expressing HEK293 cells. The intrathecal injection of GRP led to intense scratching, an effect largely reduced by either GRPR antagonists or PI3K $\gamma$ inhibitor. Scratching behavior was also induced by the intrathecal injection of an Akt activator. In a dry skin model of itch, we show that GRPR blockade or PI3K $\gamma$ inhibition reversed the scratching behavior. Altogether, these findings are highly suggestive that GRPR is expressed by the central terminals of DRG nociceptive afferents, which transmit itch via the PI3K $\gamma /$ Akt pathway.

Key words: AS605240; dry skin; GRPR; itch; PI3K $\gamma$; spinal cord

Significance Statement

Itch is the most common symptom of the skin and is related to noncutaneous diseases. It severely impairs patients' quality of life when it becomes chronic and there is no specific or effective available therapy, mainly because itch pathophysiology is not completely elucidated. Our findings indicate that the enzyme PI3K $\gamma$ is a key central mediator of itch transmission. Therefore, we suggest PI3K $\gamma$ as an attractive target for the development of new anti-pruritic drugs. With this study, we take a step forward in our understanding of the mechanisms underlying the central transmission of itch sensation.

\section{Introduction}

Itch is defined as an unpleasant sensation and emotional experience that leads to the desire or reflex to scratch (Ikoma et al., 2006). It is a recurring symptom and is a feature of both skin and systemic disorders, including chronic kidney and liver diseases, viral infections, diabetes, neurologic conditions, and certain cancers (Weisshaar and Dalgard, 2009; Davidson and Giesler, 2010). Chronic itch is a major

\footnotetext{
Received June 16, 2015; revised Nov. 4, 2015; accepted Nov. 11, 2015

Author contributions:P.J.S.P., S.T., E.A.L., and M.M.C. designed research;P.J.S.P., G.D.B.M., G.M.D., F.F.C., V.B.R., T.C.B.P., M.R.B., Y.-C.C., C.L., and S.T. performed research; P.J.S.P., G.D.B.M., G.M.D., F.F.C., Y.-C.C., C.L., S.T., and M.M.C. analyzed data; P.J.S.P., T.C.B.P., M.R.B., Y.-C.C., C.L., S.T., E.A.L., and M.M.C. wrote the paper.

This work was supported by the Fundação de Amparo à Pesquisa do Estado do Rio Grande do Sul (Grant FAPERGS/ 2012-2525-0 to M.M.C.), the National Institutes of Health (Grants R01AR057744 and R21AR067399 to E.A.L.), the Canadian Institute of Health and Research (S.T.), and the Programa de Doutorado Sanduiche no Exterior, sponsored by Coordenação de Aperfeiçoamento de Pessoal de Nível Superior (P.J.S.P.). M.M.C. is a research career awardee of the National Council for Scientific and Technological Development of Brazil. We thank Rafael F. Zanin and Tuanlian Luo for their respective assistance with flow cytometry and technical input.

The authors declare no competing financial interests.

*G.D.B.M. and G.M.D. contributed equally to this work.
}

burden that significantly affects the quality of life of patients to an extent comparable to that of chronic pain (Kini et al., 2011). Although itch and pain share nerve fibers and mechanistic and molecular overlap, their respective sensation differs (Ross, 2011). Like pain, itch remains poorly controlled and largely unresponsive to currently available pharmacotherapies (LaMotte et al., 2014). A better understanding of the pathophysiology of itch and its mechanisms of transmission is essential for the development of new therapies for this old problem.

Gastrin-releasing peptide (GRP) is a 27 aa neuropeptide widely distributed in the CNS and peripheral tissues (Majumdar

\footnotetext{
Correspondence should be addressed to either of the following: Dr. Maria M. Campos, Institute of Toxicology and Pharmacology and School of Dentistry, Pontifical Catholic University of Rio Grande do Sul, Avenida Ipiranga 6681, Partenon, 90619-900, Porto Alegre, RS, Brazil, E-mail: maria.campos@pucrs.br or camposmmartha@yahoo.com; or Dr. Ethan A. Lerner, Cutaneous Biology Research Center, Department of Dermatology, Massachusetts General Hospital and Harvard Medical School, Boston, MA 02114, E-mail: elerner@partners.org.

DOI:10.1523/JNEUROSCI.2310-15.2015

Copyright $\odot 2015$ the authors $\quad 0270-6474 / 15 / 3516272-10 \$ 15.00 / 0$
} 
and Weber, 2011). The effects of GRP are known to be mediated by the GRP receptor (GRPR), a $G_{\alpha q}$-protein-coupled receptor that classically signals via phospholipase C (PLC), leading to calcium mobilization and activation of the protein kinase $\mathrm{C}$ (Jensen et al., 2008). GRPR activation is implicated in several physiological responses, including smooth muscle contraction, hormone secretion, circadian rhythm regulation, satiety control, memory modulation, and cell growth (Gonzalez et al., 2008). This receptor is also involved in pathological states including pulmonary diseases, inflammatory conditions, and tumor growth (Jensen et al., 2008; Czepielewski et al., 2012). Sun and Chen (2007) reported that intrathecal injection of GRP induces robust and transient scratching behavior in mice, an effect absent in GRPR knock-out mice. The authors also showed that, when pruritogens were injected intradermally, GRPR mutant mice scratched significantly less compared with wild-type animals. Pain sensitivity was not compromised in GRPR mutant mice, suggesting that GRPR was an itch-specific signaling molecule in the spinal cord. GRPR continues to be the focus of numerous itch-related studies, most of which focus on upstream mechanisms and mediators, whereas the intracellular events and downstream signaling pathways have largely been overlooked, a topic that we address here.

PI3K $\gamma$ belongs to a group of highly conserved lipid kinases that participate in the intracellular signaling cascade by phosphorylating the 3'-hydroxyl ring of phosphatidylinositol and phosphoinositides, generating the second messenger $\mathrm{PIP}_{3}$, an essential step for the serine/threonine kinase Akt activation (Engelman et al., 2006). PI3K $\gamma$ has been shown to be deregulated in many disease models, including arthritis, systemic lupus erythematosus, psoriasis, multiple sclerosis, Alzheimer's disease, atherosclerosis, and allergy (Wymann et al., 2003; Barber et al., 2005; Camps et al., 2005; Fougerat et al., 2008; Passos et al., 2010; Rodrigues et al., 2010; Roller et al., 2012). We have previously reported that PI3K $\gamma$ inhibition reduces trypsin-induced scratching behavior in mice, indicating that this enzyme is involved in itch transmission (Pereira et al., 2011). Because PI3K $\gamma$ is activated downstream of GPCRs and is related to itch, we hypothesized that, in the context of pruritus, PI $3 \mathrm{~K} \gamma$ would be activated after GRPR stimulation.

Here, we used a combination of electrophysiological, pharmacological, behavioral, and molecular studies to demonstrate that central GRPR is a mediator of acute and chronic itch, signaling through the PI3K $\gamma /$ Akt pathway, and that PI3K $\gamma$ can be targeted pharmacologically to relieve GRPR-mediated itch.

\section{Materials and Methods}

Animals. Male Swiss and CD-1 mice were purchased from the Central Animal House of the Federal University of Pelotas and Charles River Laboratories, respectively. Mice were $25-30 \mathrm{~g}, 4-8$ per group, according to the experimental protocol. They were housed under standard environmental conditions of temperature $\left(22 \pm 2^{\circ} \mathrm{C}\right)$, light $(12 \mathrm{~h}$ light-dark cycle), and humidity (50-70\%), with food and water provided ad libitum. Procedures performed followed the ethical guidelines for investigations of experimental pain in conscious animals (Zimmermann, 1983) and were approved by the Institutional Animal Ethics Committee for the Pontifical Catholic University of Rio Grande do Sul and by the Institutional Animal Care and Use Committee for the Massachusetts General Hospital (13/00338 and 2012N000037, respectively). Mice were habituated to the laboratory for at least $1 \mathrm{~h}$ before experiments.

$D R G$ culture and calcium imaging. Cervical to lumbar dorsal root ganglia (DRG) from mice were dissected and maintained in DMEM (Invitrogen) containing $200 \mathrm{~mm}$ L-glutamine (Fisher Scientific), 10\% heat-inactivated FBS (Invitrogen), and $5000 \mathrm{U} / \mathrm{ml}$ penicillin and 5000 $\mu \mathrm{g} / \mathrm{ml}$ streptomycin (Fisher Scientific). Enzymatic digestion was per- formed with $1 \mathrm{mg}$ of collagenase in $1 \mathrm{ml}$ of dispase (Roche) at $37^{\circ} \mathrm{C}$ for 70 min. The collagenase/dispase solution was removed and DRG were washed and resuspended in DMEM containing 125 U DNase (SigmaAldrich) within which the ganglia were mechanically triturated using fire-polished glass pipettes. Cells were centrifuged over a 10\% BSA solution (Sigma-Aldrich) gradient, pelleted, and resuspended in neurobasal medium (Invitrogen) supplemented with B27 (Invitrogen), nerve growth factor (Invitrogen), glial cell-derived neurotrophic factor (Sigma-Aldrich), and arabinocytidine (Sigma-Aldrich). Cells were plated onto glass-bottom $35 \mathrm{~mm}$ dishes coated with $10 \mu \mathrm{g} / \mathrm{ml}$ laminin (Sigma-Aldrich) and cultured for $24 \mathrm{~h}$.

For calcium imaging experiments, neurons were loaded for $30 \mathrm{~min}$ with $10 \mu \mathrm{M}$ Fura-2 AM (Invitrogen) in neurobasal medium, washed with standard extracellular solution containing the following (in $\mathrm{mM}$ ): 145 $\mathrm{NaCl}, 5 \mathrm{KCl}, 2 \mathrm{CaCl}_{2}, 1 \mathrm{MgCl}_{2}, 10$ glucose, and 10 HEPES, pH 7.5, and imaged at room temperature. Cells were evaluated using a Nikon Eclipse $\mathrm{Ti}$ inverted microscope equipped with an Exi Aqua CCD camera (QImaging). $\mathrm{Ca}^{2+}$ flux fluorescence was measured as an absorbance ratio at 340 and $380 \mathrm{~nm}$ (F340/380) (Lambda DG4; Sutter Instruments). The 340/380 ratiometric images were analyzed using Nikon Elements AR software. Serotonin (5-HT, 3-300 $\mu \mathrm{M})$, chloroquine (CQ, 0.1-100 $\mu \mathrm{M})$, SLIGRL- $\mathrm{NH}_{2}$ (SLIGRL, 0.1-100 $\mu \mathrm{M}$ ), gastrin-releasing peptide (GRP, 0.001-1 $\mu \mathrm{M}$ ) were all from Sigma-Aldrich. GRPR antagonists (RC-3095 and PD176252, $1 \mu \mathrm{M}$ ) were from Adooq Bioscience and Tocris Bioscience, respectively. The solutions were delivered directly onto neurons at a flow rate at $2 \mathrm{ml} / \mathrm{min}$ for $20 \mathrm{~s}$ using perfusion barrels followed by buffer washout and further application. After applications of ligands, $1 \mu \mathrm{M}$ capsaicin (Tocris Bioscience) and/or $40 \mathrm{~mm} \mathrm{KCl} \mathrm{(Sigma-Aldrich)} \mathrm{were}$ applied at the end of each experiment. The criteria to determine a positive response to each compound was a raise in fluorescence (F340/F380) of 20 percent above baseline (average fluorescence recorded during the first $60 \mathrm{~s}$ of each dish).

Current-clamp recordings. At 48/72 h after plating, only small cells $(<25 \mu \mathrm{m})$ that responded to GRP in calcium imaging experiment were recorded in whole-cell mode. A multiclamp 700B amplifier, digidata 1440a digitizer and Clampex software (Molecular Devices) were used for recordings. Data were sampled at $10 \mathrm{kHz}$. Pipettes were pulled from thick-walled borosilicate glass capillaries on a Sutter Instruments P-97 and had a resistance $<3 \mathrm{M} \Omega$ when filled with the pipette solution. Capacity transients were canceled and series resistance was compensated at $\sim 80 \%$. After obtaining whole-cell configuration, cells were held at $-60 \mathrm{mV}$ for $3 \mathrm{~min}$ to allow equilibrium and only cells that had stable and low-access (generally $5 \mathrm{M} \Omega$, always $<10 \mathrm{M} \Omega$ ) resistance throughout the whole protocol were analyzed. Membrane potential was corrected for liquid junction potential $(-15 \mathrm{mV})$. Pipette solution contained the following (in $\mathrm{mm}$ ): $135 \mathrm{~K}$ gluconate, $10 \mathrm{KCl}, 1 \mathrm{MgCl}_{2}, 5 \mathrm{EGTA}$, and 10 HEPES, $300 \mathrm{mOsm}$ and $\mathrm{pH}$ 7.3. Standard external solution was obtained from Boston BioProducts and contained the following (in $\mathrm{mM}$ ): 145 $\mathrm{NaCl}, 5 \mathrm{KCl}, 2 \mathrm{CaCl}_{2}, 1 \mathrm{MgCl}_{2}, 1$ glucose, and 10 HEPES, pH 7.4.

Pain assessment. Mouse thermal latency threshold was assessed using the Hargreaves' test (Plantar Test Apparatus; Ugo Basile) 10 min after an acute capsaicin (100 $\mu \mathrm{M}$; prepared in DMSO) injection into their left hindpaw (Caterina et al., 2000). Separate groups of mice were coinjected with capsaicin $(100 \mu \mathrm{M})$ and RC-3095 (1 nmol/paw) or PD176252 (1 $\mathrm{nmol} / \mathrm{paw}$ ). The control group received the respective vehicle (DMSO).

Flow cytometry analysis. Lumbar spinal cords from mice were harvested and digested using $2 \mathrm{ml}$ of RPMI medium with $2 \%$ FBS and collagenase. Cells were stimulated with GRP $(0.001-0.1 \mu \mathrm{M})$ or saline solution for 5 and $30 \mathrm{~min}$ at $37^{\circ} \mathrm{C}$. In some cases, the cells were preincubated with the GRPR antagonist PD176252 (10, 30, and $100 \mu \mathrm{M})$ or the selective PI3K $\gamma$ inhibitor AS605240 (0.003, 0.01, and $0.03 \mu \mathrm{M})$ for $15 \mathrm{~min}$ before adding GRP. The cells were then fixed in Phosflow Buffer I for 10 min at $37^{\circ} \mathrm{C}$, washed, and permeabilized with Phosflow Perm Buffer II for 30 min on ice. Cells were then either stained with A488 anti-phosphop38 (catalog \#612594; BD Biosciences), PE anti-phospho-Akt (catalog \#560378; BD Biosciences), and APC anti-phospho-ERK 1/2 (catalog \#179109-41; eBioscience). Experiments were processed on a FACSC anto II Flow Cytometer (BD Biosciences) and analyzed using FlowJo software (TreeStar). 
Western blot analysis for GRPR, $p$-Akt, and total-Akt. For this set of experiments, mouse GRPR cDNA was cloned as a Xhol-HindIII fragment into the pcDNA3.1 ( - )hygro plasmid vector. Human embryonic kidney cells (HEK293; ATCC CRL-1573) were transfected with the GRPR plasmid DNA. HEK293 cells transfected with pcDNA3.1 (-) vector only were used as a control. Forty-eight hours after transfection, the cells were rinsed with PBS three times. Transfected HEK293 cells were incubated with either GRP (10 and $100 \mathrm{nM}$ ) or PBS at $37^{\circ} \mathrm{C}$ for 10 and 30 min. Control HEK293 cells were treated with GRP (10 and $100 \mathrm{~nm}$ ) or PBS in a similar manner. A subset of transfected HEK293 cells remained untreated and served as a negative control. After incubation, the cells were harvested and lysed by protein immunoprecipitation lysis buffer (Thermo Fisher Scientific) with proteinase inhibitor and phosphatase inhibitor (Roche Diagnostics). Cell lysates were centrifuged at $4^{\circ} \mathrm{C}$ for 20 $\mathrm{min}$. The supernatants were collected and protein concentrations were determined by BCA assay. Equal amounts of cell lysates were loaded onto NuPAGE Novex $4-12 \%$ Bis-Tris mini gels, electrophoresed, and transferred to PVDF using standard protocols. The blot was first probed with anti-GRPR (catalog \#ab39883; Abcam), anti-Akt antibody (catalog \#9272S; Cell Signaling Technology), anti-phospho-Akt (catalog \#051003; Millipore), and HRP-conjugated anti-GAPDH (catalog \#3683; Cell Signaling Technology) antibody to identify the control GAPDH band at $37 \mathrm{kDa}, 24 \mathrm{~h}$ at $4^{\circ} \mathrm{C}$. Then, the blots were incubated with HRP-conjugated goat anti-rabbit antibody, followed by detection of the ECL substrate.

Scratching behavior. To assess acute and chronic itch, the behavioral tests were performed as described previously with minor modifications (Sun and Chen, 2007; Akiyama et al., 2010; Maciel et al., 2014). One day before the experimental sessions, either the lumbar region or nape of the neck was shaved. On the day of experiments, mice were placed individually into acrylic chambers for at least $30 \mathrm{~min}$ to adapt to the new environment. Thereafter, mice were removed and injected intrathecally with $5 \mu \mathrm{l}$ of gastrin-releasing peptide (GRP, $1 \mathrm{nmol} / \mathrm{site}$ ). Immediately after the injection, mice were returned to the chambers and recorded for $60 \mathrm{~min}$.

In a different set of experiments, separate groups of mice were injected intradermally with $50 \mu \mathrm{l}$ of compound 48/80 (10 $\mu \mathrm{g} / \mathrm{site})$, CQ (200 $\mu \mathrm{g} /$ site), trypsin $(200 \mu \mathrm{g} / \mathrm{site})$, or $\mathrm{H}_{2} \mathrm{O}_{2}(0.3 \%)$ into the nape of the neck. The scratching behavior was recorded for $40 \mathrm{~min}$ after the injections.

For the dry skin model, chronic itch was induced by application of a gauze soaked with a mixture of acetone and diethylether (1:1) on the nape of the mouse neck for $15 \mathrm{~s}$, immediately followed by the application of distilled water for $30 \mathrm{~s}$ (AEW treatment), twice daily for $5 \mathrm{~d}$. A different group of animals received distilled water application only, for a $45 \mathrm{~s}$ period (DW group). On the fifth day, the scratching behavior was recorded for $30 \mathrm{~min}$ after the last application.

We also investigated whether the direct activation of Akt would be able to induce scratching behavior. Mice received an intrathecal injection of 5 $\mu \mathrm{l}$ containing the Akt activator SC79 (20 $\mu \mathrm{g}$ /site; Sigma-Aldrich). Immediately after the injection, mice were returned to the chambers and the scratching bouts were recorded for $40 \mathrm{~min}$.

For all the experimental models, the scratching behavior was measured as the number of scratches with hindpaws close to the treated site or at the mouse dorsum. Scratching behind the ears, but not on the face, was also taken into account.

All of the intrathecal injections in this study were performed in conscious animals according to the method described previously (Quintão et al., 2008) with some modifications. A 30-gauge needle connected to a Hamilton microsyringe was introduced through the skin and a volume of $5 \mu \mathrm{l}$ was injected between the L5 and L6 vertebral spaces.

Pharmacological treatments for itch studies. Mice were treated with the pseudopeptide GRPR antagonist, RC-3095 (1 nmol/site), administered intrathecally $10 \mathrm{~min}$ before the injection of GRP or the last application of AEW on the fifth day to investigate a possible role of GRPR in chronic itch. We also tested the nonpeptide GRPR/neuromedin B receptor (NMBR) antagonist PD176252 given intraperitoneally (1 and $5 \mathrm{mg} / \mathrm{kg}$ ) $30 \mathrm{~min}$ before the injection of GRP or $5 \mathrm{mg} / \mathrm{kg}$ intraperitoneally $30 \mathrm{~min}$ before the last application of AEW on the fifth day. Previous data indicated the relevance of PI3K $\gamma$ in trypsin-evoked itch. Therefore, to assess whether PI3K $\gamma$ could be involved in GRPR signaling, the selective PI3K $\gamma$ inhibitor AS605240 (0.01-10 mg/kg) was given by gavage $30 \mathrm{~min}$ before GRP ( $1 \mathrm{nmol} /$ site) injection or $30 \mathrm{~min}$ before the last application of AEW protocol.

To further evaluate the site of action of AS605240 ( 1 and $3 \mu \mathrm{g} / \mathrm{site}$ ), the compound was intrathecally coinjected with GRP. PD176252 (8.5 nmol/ site) and AS605240 (3 $\mu \mathrm{g} / \mathrm{site})$ were also injected intrathecally $10 \mathrm{~min}$ before the last application of AEW.

The doses of the pharmacological modulators were selected based on the literature and on pilot experiments (Camps et al., 2005; Merali et al., 2006; Pereira et al., 2011; Su and Ko, 2011). PD176252 and AS605240 (both purchased from Tocris Bioscience) were prepared daily and dissolved in their vehicles, $1 \%$ Tween 20 in saline solution or $0.5 \%$ carboxymethylcellulose/0.25\% Tween 20, respectively. RC-3095 (Adooq Bioscience) was prepared on the day of the experiments in DMSO $0.1 \%$ in saline solution. Control groups received the respective vehicles by the same route of administration. The final concentrations of solvents did not display any significant effect per se. PD176252 is a competitive antagonist with a high affinity for $\operatorname{NMBR}\left(K_{\mathrm{i}}=0.17 \mathrm{nM}\right)$ and $\operatorname{GRPR}\left(K_{\mathrm{i}}=\right.$ $1.0 \mathrm{nM}$ ) receptors (Ashwood et al., 1998). However, it has been shown that PD176252 specifically inhibited GRP binding to GRPR $\left(\mathrm{IC}_{50}=30\right.$ $\mathrm{nM}$ ) on lung cancer cells and has the same effects that the selective pseudopeptide antagonist RC-3095 on myometrium contractility, where the GRP/GRPR system is involved (Moody et al., 2003; Tattersall et al., 2012). AS605240 is classified as a selective inhibitor of PI3K $\gamma\left(\mathrm{IC}_{50}=8\right.$ $\mathrm{nM}$ ), with 30 -fold selectivity over PI $3 \mathrm{~K} \delta$ and PI $3 \mathrm{~K} \beta$ and 7.5-fold selectivity over PI3K $\alpha$, as indicated by the supplier (Camps et al., 2005).

Statistical analysis. Data are presented as the mean \pm SEM of 6-8 animals per group for behavior experiments. In the case of flow cytometry analysis, an experimental $n$ of 4 per group was used. For Western blot analysis and $\mathrm{Ca}^{2+}$ imaging, an experimental $n$ of 3 independent experiments was used. Statistical comparison of the results was performed by paired or unpaired Student's $t$ test or by one-way ANOVA followed by Tukey's test or Student's $t$ test. Statistical significance was defined as $p<$ 0.05. GraphPad Prism software version 5.0 was used for statistical analysis.

\section{Results}

\section{GRP activates capsaicin-sensitive DRG neurons}

GRP has long been known to control circadian rhythm, satiety, memory modulation centrally and it has been shown recently to be involved in itch transmission. It is as yet unclear where and how GRP induces scratching behavior when injected intrathecally. Because pruritogens including 5-HT, CQ, and SLIGRL$\mathrm{NH} 2$ were shown to induce calcium flux directly in DRG neurons (Liu et al., 2009; Akiyama et al., 2010), we hypothesized that some of GRP actions could be, at least in part, mediated by DRG afferent neurons. Here, we confirm previous findings showing that 5-HT (Fig. 1A), CQ (Fig. 1B), and SLIGRL (Fig. 1C) induced a transient and concentration-dependent calcium flux in cultured DRG neurons. Our data also highlight that GRP $(0.001-1 \mu \mathrm{M})$ induced calcium flux in DRG neurons, an effect relatively stronger (higher amplitude) and broader (higher number of cells activated) than the other agents (Fig. 1D). GRP-responsive cells were mostly small-diameter (soma of $<300 \mu \mathrm{m}^{2}$; Fig. $1 E$ ), capsaicinsensitive neurons (Fig. $1 F$ ). These data are consistent with the presence of functional GRPR on TRPV1 ${ }^{+}$DRG neurons. Next, we performed whole-cell patch-clamp on calcium imaging and identified GRP-responsive cells. When exposed to GRP $(0.1 \mu \mathrm{M})$, nociceptors (diameter $<25 \mu \mathrm{m}$ ) showed significant depolarization of the resting membrane potential (RMP) of $\sim 20 \mathrm{mV}$, which led to action potential firing $(n=5, p=0.001)$. Neurons prescreened with calcium imaging that were non-GRP responsive showed no difference in RMP $(-73.0 \pm 3.5 \mathrm{mV}$ vs $-72.0 \pm 4.5$ $\mathrm{mV}, n=3 ; p=0.47$ ) when reexposed to GRP (data not shown). The specificity of GRP responses for GRPR was assessed and showed that GRP-induced $\mathrm{Ca}^{2+}$ flux was reversed by the cotreat- 
A

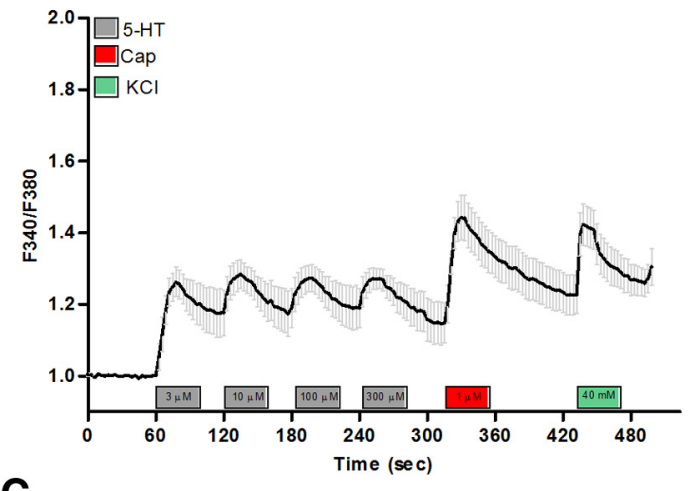

C

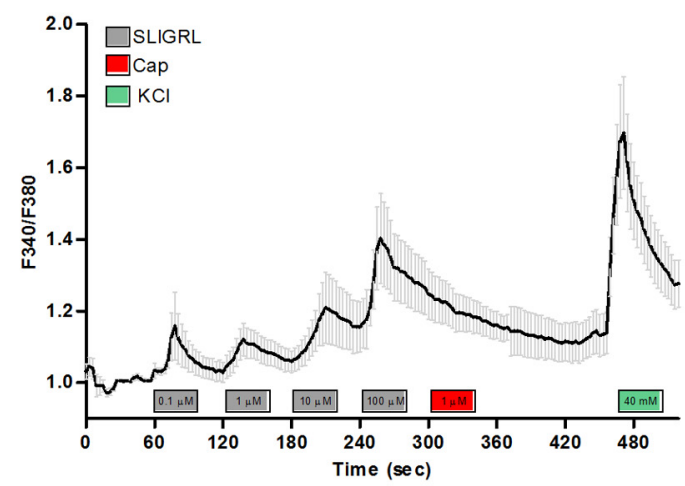

E

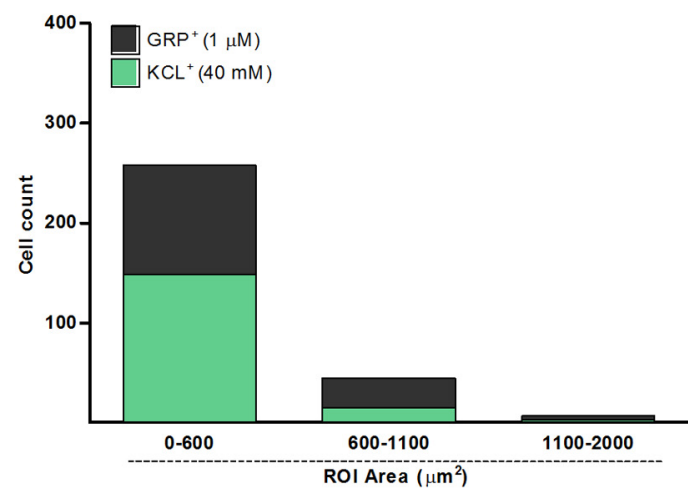

G

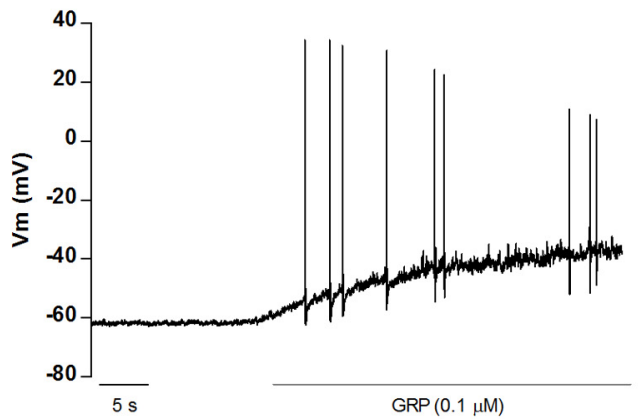

B

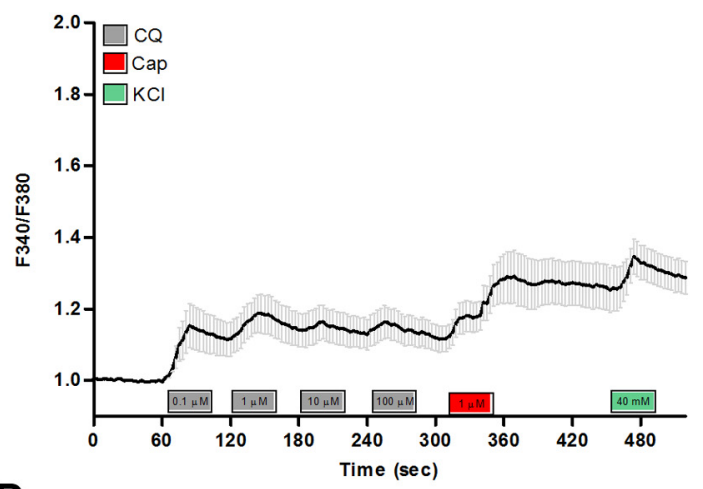

D

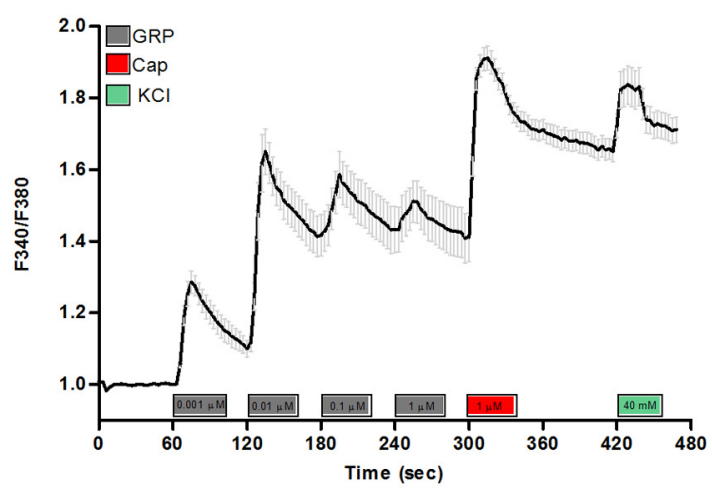

$\mathbf{F}$

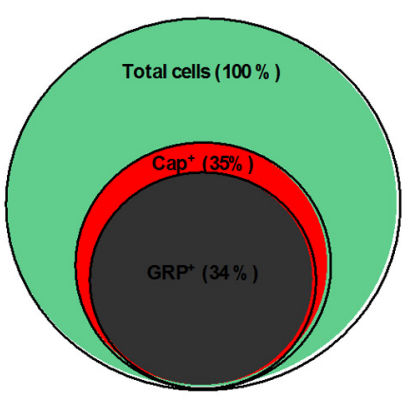

H

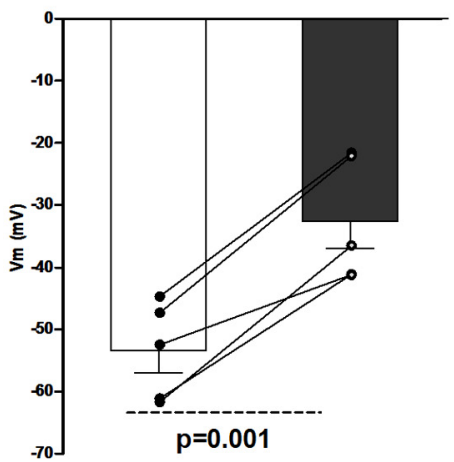

Figure 1. GRP activates capsaicin-sensitive DRG neurons from naive mice. Data show the average calcium flux in responsive neurons exposed to increasing concentration of $(\boldsymbol{A}) 5-\mathrm{HT}(3-300 \mu \mathrm{M})$,

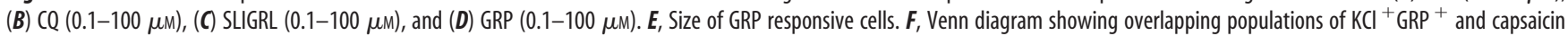
responsive neurons. $\boldsymbol{G}, \boldsymbol{H}$, Current-clamp recordings of GRP-responsive cells $(<25 \mu \mathrm{m})$ prescreened with calcium imaging and retreated with GRP $(0.1 \mu \mathrm{m})$ showed a transient depolarization of the $\operatorname{RMP}(53.5 \pm 3.5 \mathrm{mV}$ vs $32.5 \pm 4.5 \mathrm{mV}, n=5)$ and action potential firing. Significant depolarization of the RMP before and after GRP treatment was calculated by paired Student's $t$ test $(p=0.001)$. Respectively, a total of $524(\boldsymbol{A}), 369(\boldsymbol{B}), 375(\boldsymbol{C}), 533(\boldsymbol{D}), 302(\boldsymbol{E}), 533(\boldsymbol{F}), 5(\boldsymbol{G})$, and $5(\boldsymbol{H})$ cells were analyzed. 
A

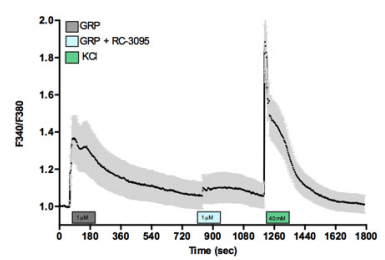

B

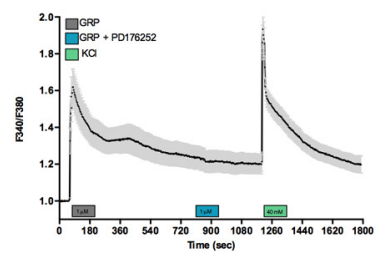

C

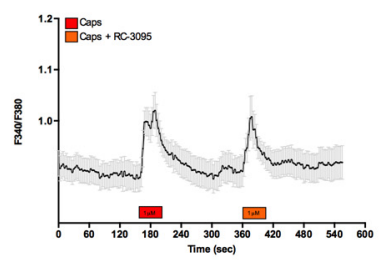

D

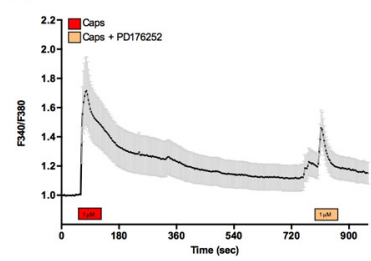

E

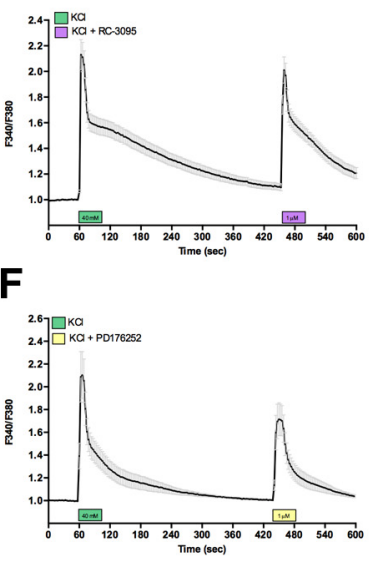

G

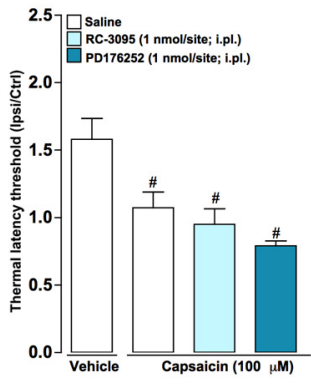

Figure 2. The GRPR antagonists did not affect capsaicin- or KCl-induced calcium response in DRG neurons nor capsaicin-induced thermal hyperalgesia. Effects of the cotreatment with the GRPR antagonists $(\boldsymbol{A}, \boldsymbol{C}, \boldsymbol{E}) \mathrm{RC}-3095(1 \mu \mathrm{M})$ or ( $\boldsymbol{B}, \boldsymbol{D}, \boldsymbol{F})$ PD176252 $(1 \mu \mathrm{m})$ on $\mathrm{Ca}^{2+}$ flux induced by $(\boldsymbol{A}, \boldsymbol{B}) \mathrm{GRP}(1 \mu \mathrm{M}),(\boldsymbol{C}, \boldsymbol{D})$ capsaicin $(1 \mu \mathrm{M})$, or $(\boldsymbol{E}, \boldsymbol{F}) \mathrm{KCl}(40 \mathrm{mM}) . \boldsymbol{G}$, Effects of the GRPR antagonists on capsaicin-induced thermal hyperalgesia. Data are expressed as mean \pm SEM. One-way ANOVA followed by Tukey's test $(n=8$ mice per group). Significant differences from saline injection are indicated by \#p < 0.05. Respectively, a total of $132(\boldsymbol{A}), 196(\boldsymbol{B}), 59(\boldsymbol{C}), 14(\boldsymbol{D}), 24(\boldsymbol{E})$, and $137(\boldsymbol{F})$ cells were analyzed.

ment with the GRPR antagonists RC-3095 ( $1 \mu \mathrm{M}$; Fig. 2A) and PD176252 ( $1 \mu \mathrm{M}$; Fig. $2 B$ ), whereas the response to capsaicin and $\mathrm{KCl}$ was preserved (Fig. $2 C-F$ ). We also showed that the GRPR antagonists did not affect capsaicin-induced thermal hyperalgesia (Fig. 2G), suggesting selectivity only for GRPmediated effects.

\section{GRPR signals through the PI3K $\gamma /$ Akt pathway}

Sun and colleagues (Sun and Chen, 2007; Sun et al., 2009) reported that GRPR is expressed in naive mouse spinal cord. To gain further insight into the potential signaling pathways downstream of GRPR, we treated ex vivo mouse spinal cords with GRP (0.01-0.1 $\mu \mathrm{M})$ and assessed the activation of different MAP kinases by flow cytometry of dissociated spinal neurons. GRP ( 0.001 and $0.1 \mu \mathrm{M}, 5$ and $30 \mathrm{~min})$ did not affect p38 and ERK1/2 activation (Fig. $3 A, B$ ), but significantly increased Akt phosphorylation after a $5 \mathrm{~min}(0.003-0.1 \mu \mathrm{M})$ or $30 \mathrm{~min}$ $(0.1 \mu \mathrm{M})$ (Fig. $3 C, D)$ exposure. Pretreatment with the nonpeptide GRPR antagonist PD176252 (30 and $100 \mu \mathrm{M}$; Fig. 3E) or the PI3K $\gamma$-selective inhibitor AS605240 (0.01 and $0.03 \mu \mathrm{M}$; Fig. $3 F$ ) prevented, in a concentration-dependent manner, GRP-induced Akt phosphorylation. These data indicate that centrally expressed GRPR signals at least partly via the PI3K $\gamma /$ Akt pathway. To refine evidence on the intracellular signaling cascade downstream of GRPR, we also performed Western blots from HEK293 cells transiently expressing GRPR and exposed to GRP $(0,10$, or $100 \mathrm{nM})$ for 10 or $30 \mathrm{~min}$. The expression levels of GRPR, p-Akt, and total Akt were quantified and ratioed over GAPDH (Fig. 4A,B). Compared with PBS, GRP significantly increased the p-Akt/Akt protein levels, an effect limited to the GRPR-transfected cells. These data are consistent with the hypothesis that GRPR stimulation leads to activation of the PI3K $\gamma /$ Akt pathway.

\section{GRP- and dry-skin-induced itch are reversed by GRPR and PI3K $\gamma$ blockade}

The intrathecal delivery of GRP induces scratching behavior in mice (Sun and Chen, 2007; Sun et al., 2009), an effect that we reproduced here (GRP, $1 \mathrm{nmol} /$ site, i.t.; Fig. 5). Such scratching behavior was prevented by local treatment with RC-3095 ( $1 \mathrm{nmol} /$ site, i.t.) and systemic treatment with PD176252 (1 and $5 \mathrm{mg} / \mathrm{kg}$, i.p.) (Fig. 5A). PD176252 also reduced the scratching induced by other pruritogens, namely compound 48/80, CQ, trypsin, and $\mathrm{H}_{2} \mathrm{O}_{2}$, while displaying different profiles of inhibition (Table 1 ).

Although there is literature focusing on the role of GRPR and its upstream mediators, in itch, a careful look into the downstream signaling pathways activated by this receptor is missing. Here, we assessed the effects of the selective PI3K $\gamma$ inhibitor AS605240 on the scratching behavior induced by GRP. A significant decrease in the total number of scratches was observed when mice were treated orally with AS605240 (0.01-3 mg/kg; Fig. 5B). To further assess whether the PI3K $\gamma$ inhibitor had any effect at the spinal level, AS605240 (1 and 3 $\mu \mathrm{g} / \mathrm{site}$ ) was coinjected intrathecally with GRP ( $1 \mathrm{nmol} / \mathrm{site})$ in conscious animals. Intrathecal treatment with AS605240 resulted in significantly diminished GRP-evoked scratching behavior compared with mice that received GRP and vehicle treatment (Fig. 5C).

Next, we used the dry skin model (AEW) to investigate the implication of GRPR in chronic itch. As depicted in Figure 5D, AEW triggered significant scratching behavior compared with distilled water (control) and the intrathecal administration of either GRPR antagonists RC-3095 ( $1 \mathrm{nmol} / \mathrm{site}$ ) or PD176252 ( $8.5 \mathrm{nmol} / \mathrm{site})$ significantly affected this behavior. In addition, systemic treatment with PD176252 (5 mg/kg, i.p.) significantly reduced the scratch bouts in AEW mice to values similar to those seen in water-treated controls. These data highlight the relevance of GRPR in this chronic model of itching. We next investigated whether PI3K $\gamma$ might be relevant in the AEW model. AS605240 administered orally $(0.3-10 \mathrm{mg} /$ kg; Fig. 5E) significantly diminished dry-skin-induced itch. The spinal effects of AS605240 (3 $\mu \mathrm{g} / \mathrm{site})$ were also evaluated in the dry skin model and significantly reduced the scratching behavior caused by AEW (Fig. 5F). These results demonstrate that GRPR is involved in dry skin itch, along with PI3K $\gamma$, the latter acting as a key downstream signaling molecule in the GRP/GRPR system. The selectivity of the PI3K $\gamma$ inhibitor for itch sensation over nociception was also assessed and AS605240 did not affect formalin-induced orofacial pain (data not shown). Altogether, our findings indicate that the gamma 

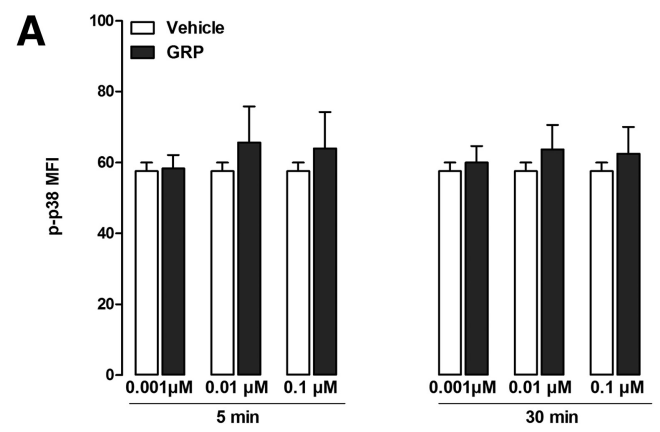

C
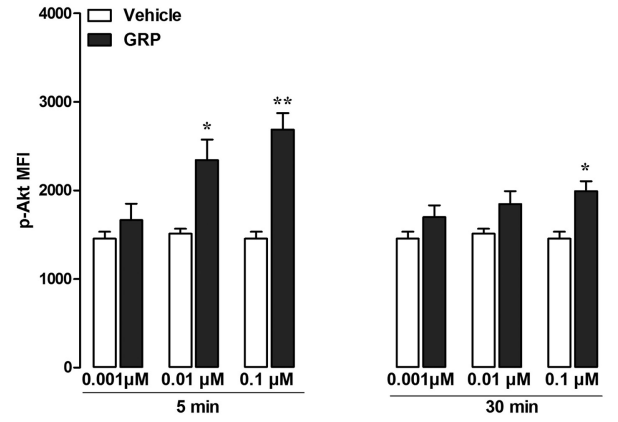

$\mathbf{E}$

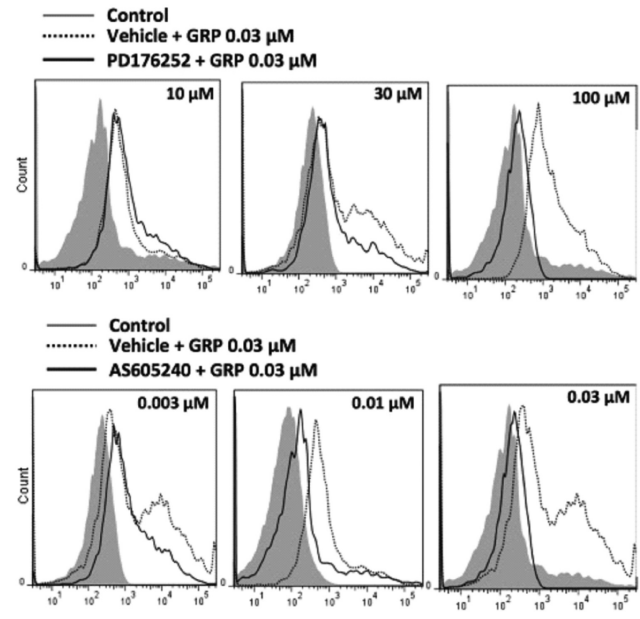

B

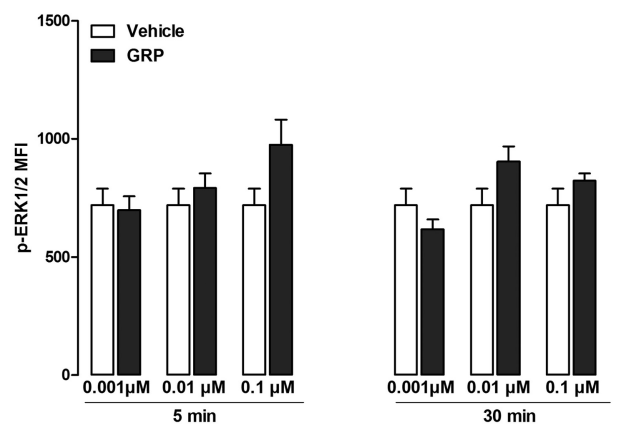

D

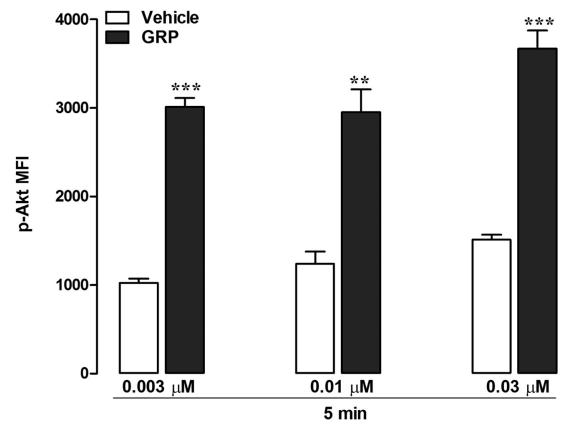

$\mathbf{F}$

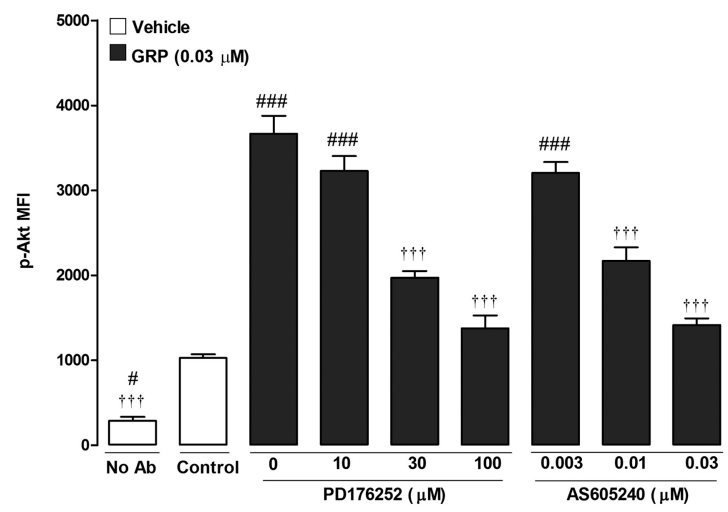

Figure 3. GRP triggers Akt phosphorylation in ex vivo mouse spinal cords. Assessment of $(\boldsymbol{A}) \mathrm{p} 38,(\boldsymbol{B})$ ERK1/2, and ( $\boldsymbol{C}$ Akt phosphorylation in ex vivo mouse spinal cords exposed to GRP (0.001-0.1 $\mu \mathrm{M})$. D, Treatment with different concentrations (0.003-0.03 $\mu \mathrm{m}$ ) of GRP on Akt phosphorylation. E, Representative flow cytometry histograms for Akt phosphorylation in spinal cords treated with saline (control; gray), GRP (0.03 $\mu \mathrm{m}$; dashed line), or GRP $(0.03 \mu \mathrm{m})$ after incubation with the GRPR antagonist PD176252 (10, 30, and $100 \mu \mathrm{m}$; top, solid back line) or the selective PI3K $\gamma$ inhibitor AS605240 ( $0.003,0.01$, and $0.03 \mu \mathrm{m}$; bottom, solid back line). $\boldsymbol{F}$, Quantification of mean fluorescence intensity (MFI) for p-Akt after treatment with saline or GRP ( $0.03 \mu \mathrm{M})$ in the presence of the GRPR antagonist PD176252 (10,30, and $100 \mu \mathrm{M})$ or the selective PI3K $\gamma$ inhibitor AS605240 $(0.003,0.01$, and $0.03 \mu \mathrm{M})$. Data represent mean \pm SEM. Unpaired Student's $t$ test or one-way ANOVA followed by Tukey's sest ( $n=4$ mice per group). Significant differences in comparison with vehicle incubation, control, or GRP are indicated by ${ }^{*} p<0.05,{ }^{* *} p<0.01,{ }^{* * *} p<0.001$, \#\#\#p $<0.001$, and $+t+p<0.001$, respectively.

isoform of $\mathrm{PI} 3 \mathrm{~K}$ is important in the spinal transmission of GRP/GRPR-mediated itch.

\section{Spinal Akt activation induces scratching behavior in mice} Given that the PI3K $\gamma$ signals through Akt, we assessed the impact of direct spinal Akt activation on mouse scratching behavior. The intrathecal injection of the Akt activator SC79 (20 $\mu \mathrm{g} /$ site) induced significant itching compared with vehicle-injected animals (Fig. 6). These data reveal that the spinal activation of Akt can trigger itch directly.

\section{Discussion}

The study of itch has blossomed and significant progress has been made in the past 10 years. Sun and colleagues (Sun and
Chen, 2007; Sun et al., 2009) reported that GRPR mediates itch sensation, but not pain, in the spinal cord, suggesting that this receptor is part of an itch-specific pathway. Since then, GRP and GRPR have been the subjects of several studies, some of which challenge the results of others, but always indicate their relevance in pruritus (Sun and Chen, 2007; Mishra and Hoon, 2013; Liu et al., 2014; Solorzano et al., 2015). The present study brings additional insights to this field.

Pruritogens, including 5-HT, CQ, and SLIGRL- $\mathrm{NH}_{2}$, evoke $\mathrm{Ca}^{2+}$ response in DRGs (Liu et al., 2009; Akiyama et al., 2010) and our data confirmed these findings. We also investigated the functionality of GRPR in DRG sensory neurons by stimulating 
A

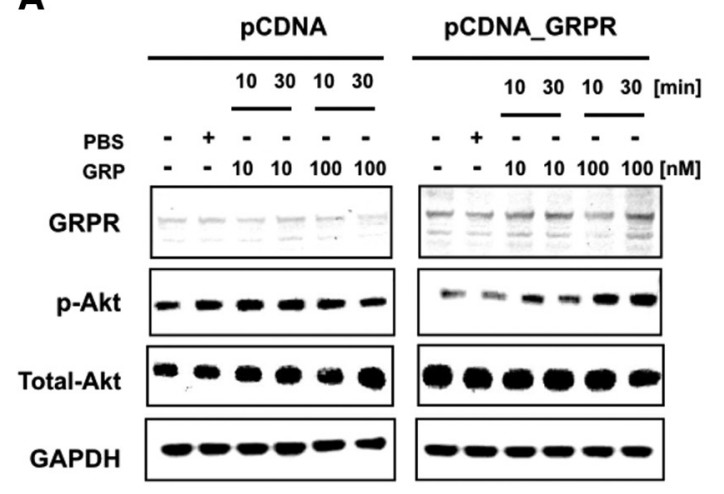

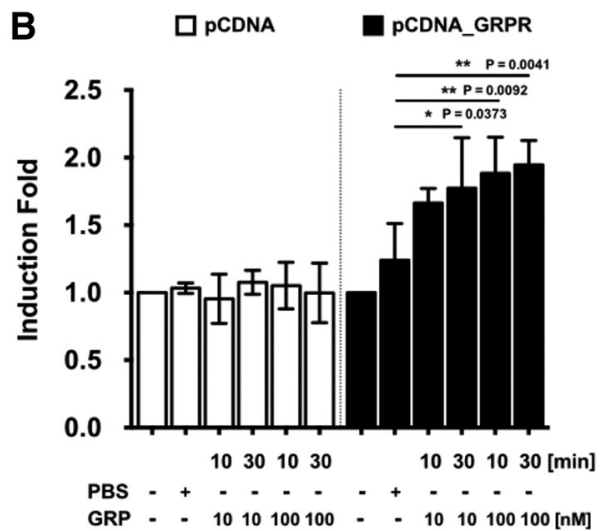

Figure 4. GRP activates the PI3K $\gamma /$ Akt pathway in HEK293 cells transfected with GRPR. A, Representative Western blots of GRPR, p-Akt, total Akt, and GAPDH in HEK293 transiently expressing GRPR and treated with GRP $(0,10$ or $100 \mathrm{~nm})$ for 10 or $30 \mathrm{~min}$. $\boldsymbol{B}$, Bar graph shows quantification of p-Akt/total Akt expression. Data are expressed as mean \pm SEM of three independent experiments. One-way ANOVA followed by Tukey's test Significant differences from PBS are indicated by ${ }^{*} p<0.05$, ${ }^{* *} p<0.01$.
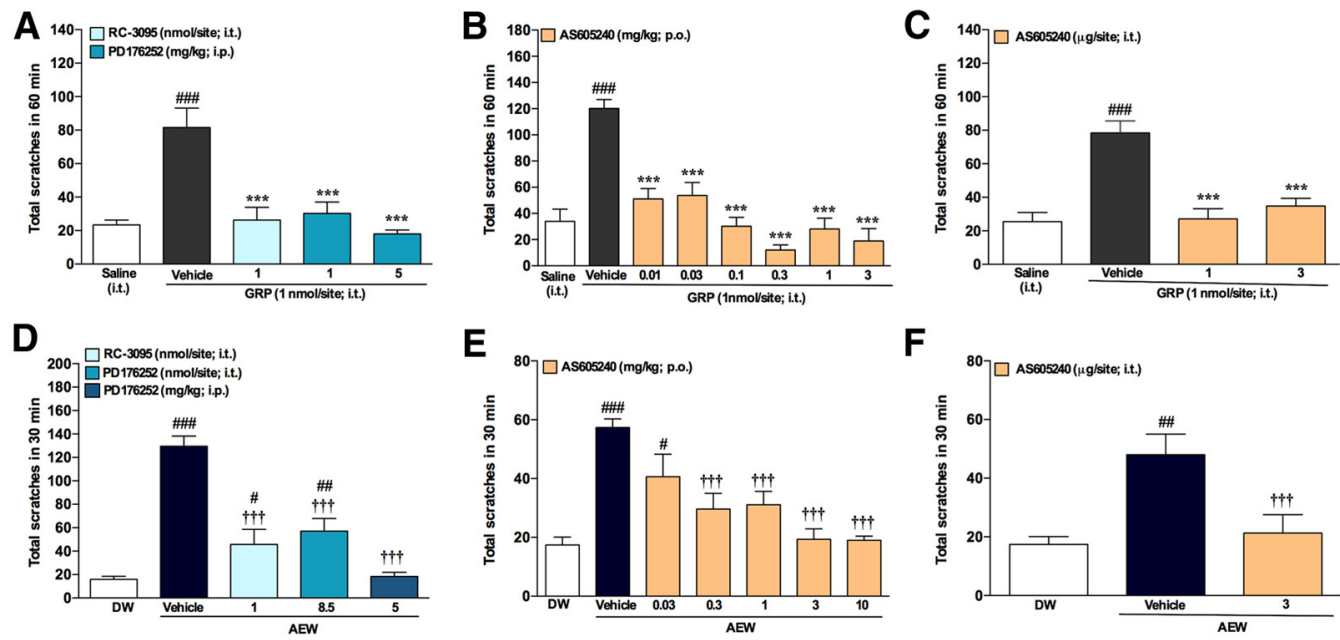

Figure 5. GRPR blockade or PI3K $\gamma$ inhibition reversed GRP- and dry-skin-induced itch. $A$, Effects of the GRPR antagonists RC-3095 (1 nmol/site, i.t.) and PD176252 (1 and $5 \mathrm{mg} / \mathrm{kg})$ on GRP-induced itch. $\boldsymbol{B}$, Effects of the oral treatment with the selective PI3K $\gamma$ inhibitor AS605240 $(0.01-3 \mathrm{mg} / \mathrm{kg})$ on scratching behavior evoked by GRP. C, Intrathecal coinjection of GRP (1 $\mathrm{nmol} / \mathrm{site})$ and AS605240 (1 and $3 \mu \mathrm{g} / \mathrm{site}$ ). Dry skin itch (AEW) is alleviated after treatment with (D) RC-3095 (1 nmol/site, i.t.) or PD176252 (8.5 nmol/site, i.t. or $5 \mathrm{mg} / \mathrm{kg}$, i.p.) before the last application of AEW, (E) AS605240 (0.03-10 mg/kg; p.o.), 30 min before the last application of AEW, or $(\boldsymbol{F})$ AS605240 (3 $\mu \mathrm{g} / \mathrm{site}$, i.t.) injected $10 \mathrm{~min}$ before the last application of AEW. Data are expressed as mean \pm SEM. One-way ANOVA followed by Tukey's test ( $n=8$ mice per group). Significant different from saline injection or distilled water treatment, GRP injection, or AEW treatment are indicated by \#\#p $<0.01$; \#\#\#, ${ }^{* * *} p<0.001$; and $++t p<0.001$.

Table 1. Effects of treatment with the selective and non-peptide GRPR antagonist PD176252 on the scratching behavior elicited by different pruritogens in mice

\begin{tabular}{llll}
\hline & \multicolumn{3}{l}{ No. of scratching bouts } \\
\cline { 2 - 4 } Pruritogen & Vehicle & PD176252 $(1 \mathrm{mg} / \mathrm{kg})$ & PD176252 $(5 \mathrm{mg} / \mathrm{kg})$ \\
\hline Compound $48 / 80(10 \mu \mathrm{g} / \mathrm{site})$ & $67 \pm 5$ & $23 \pm 10^{* *}$ & $29 \pm 4^{* *}$ \\
Chloroquine $(200 \mu \mathrm{g} / \mathrm{site})$ & $75 \pm 8$ & $29 \pm 4^{*}$ & $13 \pm 3^{* *}$ \\
Trypsin $(200 \mu \mathrm{g} / \mathrm{site})$ & $68 \pm 3$ & $54 \pm 6^{\text {NS }}$ & $16 \pm 2^{* *}$ \\
$\mathrm{H}_{2} \mathrm{O}_{2}(0.3 \% / \mathrm{site})$ & $44 \pm 7$ & $14 \pm 4^{* *}$ & $06 \pm 2^{* *}$ \\
\hline
\end{tabular}

Shown are the total number of scratches after intradermal injection of different pruritogens. Data represent mean \pm SEM.

${ }^{*} p<0.05$, ${ }^{* *} p<0.01$, one-way ANOVA followed by Tukey'stest ( $n=6-8$ mice per group), statistically significant when comparing PD176252-treated groups with control vehicle-treated animals. NS, Nonsignificant when comparing PD176252-treated groups with control vehicle-treated animals.

isolated culture DRG neurons with GRP. The present data show that GRP can excite small-size, capsaicin-sensitive DRG neurons and two types of GRPR antagonists blocked these responses. Conversely, GRPR antagonism did not affect capsaicin and $\mathrm{KCl}$-induced $\mathrm{Ca}^{2+}$ flux or capsaicin-induced thermal hyperalgesia.
Intrathecal GRP acts via GRPR to induce scratching behavior; however, the mechanisms downstream of GRPR activation remain unclear (Sun and Chen, 2007; Liu et al., 2011; Mishra and Hoon, 2013; Kardon et al., 2014). Czepielewski et al. (2012) demonstrated that GRP induces neutrophil chemotaxis through GRPR via p38, ERK $1 / 2$, and PI3K activation. Here, we did not observe p38 or ERK 1/2 activation when spinal cords were treated with GRP, but did show that GRP induces Akt phosphorylation, a marker of PI3K activation. Using the potent selective PI3K $\gamma$ isoform inhibitor AS605240 instead of a pan-inhibitor of PI3K, we demonstrated that PI3K $\gamma$ is activated downstream of GRP/ GRPR. We confirmed that p-Akt is significantly increased after GRP incubation by performing Western blots on HEK293 cells transiently expressing GRPR. Again, these findings indicate that PI3K $\gamma$ is a major downstream effector of the GRP/GRPR system.

Recent studies demonstrated that the pseudopeptide GRPR antagonist RC-3095 reduces GRP-evoked itch (Inan et al., 2011; Sukhtankar and Ko, 2013; Akiyama et al., 2014). Here, we show that RC-3095 and the nonpeptide antagonist PD176252 mark- 


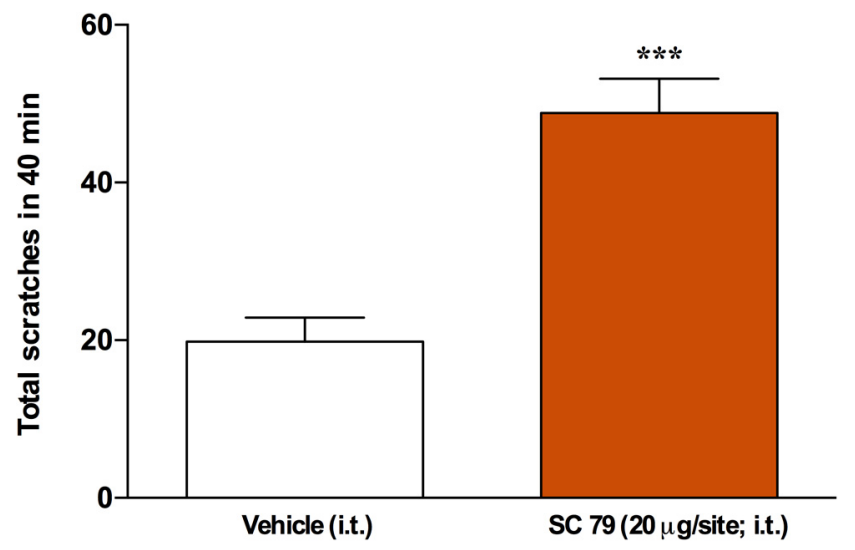

Figure 6. Spinal Akt activation triggers scratching behavior in mice. Scratching behavior induced by intrathecal injection of the Akt activator $S C 79$ (20 $\mu \mathrm{g} / \mathrm{site})$. Data represent mean \pm SEM. Student's $t$ test ( $n=6$ mice per group). ${ }^{* * *} p<0.001$.

edly reversed GRP-induced itch. As demonstrated before (Sun and Chen, 2007), GRPR deletion or antagonism prevents the scratching behavior elicited by the intradermal application of compound 48/80 and CQ, an effect that we replicated herein with PD176252 and extended to $\mathrm{H}_{2} \mathrm{O}_{2}$ and trypsin, reinforcing the central role of GRPR in itch transmission.

Considering the lack of data on the signaling pathways downstream of the GRP/GRPR system in the context of central itch transmission, we tested the effects of the potent and selective PI3K $\gamma$ inhibitor AS605240 on GRP-induced itch. Oral treatment with AS605240 significantly reduced the GRP-induced scratching behavior. Accordingly, a previous study from our group showed that AS605240 relieves trypsin-mediated scratching behavior in mice (Pereira et al., 2011). We further assessed whether AS605240 displays local spinal effect when coinjected with GRP and observed that the itching response was significantly diminished. This clearly suggests that PI3K $\gamma$ plays a key role in acute itch spinal transmission involving GRP/GRPR. PI3K $\gamma$ acts via Akt phosphorylation and, to support PI3K $\gamma$ as an important itch transducer, we showed that the direct activation of spinal Akt after the intrathecal administration of SC79 induced scratching behavior in mice.

The GRPR/PI3K $\gamma$ pathway could also be involved in chronic itching, a more clinically relevant condition. We addressed this using the dry skin model (AEW) of itch and tested the local effects of RC-3095 and the systemic and local effects of PD176252 and AS605240. GRPR blockade, as well as PI3K $\gamma$ inhibition, significantly reduced the scratching behavior induced by skin dryness. Mice treated with RC-3095, PD176252, and AS605240 behaved normally and did not exhibit apparent adverse effects, sedation or impaired motor functions.

PD176252 is a competitive antagonist of the two bombesin receptor subtypes. We confirmed our findings with PD176252 using a second and selective GRPR antagonist (RC-3095) and are therefore confident that the responses that we observed can be ascribed to GRPR. In the case of AS605240, it has been classified as a potent inhibitor of PI3K $\gamma\left(\mathrm{IC}_{50}=8 \mathrm{nM}\right)$, with a 30 -fold selectivity over $\mathrm{PI} 3 \mathrm{~K} \delta$ and $\mathrm{PI} 3 \mathrm{~K} \beta$ and a 7.5 -fold selectivity over PI3K $\alpha$ (Camps et al., 2005). The initial study that presented the AS605240 compound showed that treatment with AS605240 or PI3K $\gamma$ knock-out mice equally reversed inflammation in two models of collagen-induced arthritis (Camps et al., 2005). The authors also tested the specificity of AS605240 against a panel of 50 kinases and only found inhibitory activity against PI3K $\gamma$.
Given this body of literature, we are confident that our data with AS605240 can be ascribed to PI3K $\gamma$.

Our findings that AS605240 reduces acute and chronic itch are consistent with several other studies showing that PI3K $\gamma$ inhibition or PI3K $\gamma$ knock-out decreases inflammation in a series of rodent models of inflammation (Barber et al., 2005; Camps et al., 2005; Fougerat et al., 2008; Passos et al., 2010; Peng et al., 2010; Roller et al., 2012). However, our findings contrast with a study published by Lee et al. (2011) showing that scratching behavior induced by intradermal injection of histamine or SLIGRL$\mathrm{NH}_{2}$, but not CQ, is increased in PI3K $\gamma$ knock-out mice, an effect not reproduced pharmacologically. Explanations for these discrepant results are numerous and include differences in pruritogens (histamine vs GRP) and routes of administration (intradermal vs intrathecal) tested. It is also plausible that PI3K $\gamma$ knock-out mice develop compensatory mechanisms. For example, both PLC and PI3K $\gamma$ signal using $\mathrm{PIP}_{2}$, which, in the absence of the PI3K $\gamma$ input, might lead to higher PIP $_{2}$ availability and consequent increase in PLC-dependent pathways. Theefore, the histamine/H1R complex, which typically leads to TRPV1 sensitization via PLC, might be increased in PI3K $\gamma$ knock-out mice. Given that TRPV1 knock-out animals have reduced histaminergic itch (Shim et al., 2007), compensatory pathways might explain the unexpected findings of Lee et al. (2011).

A previous study demonstrated that PI $3 \mathrm{~K} \delta$ and PI $3 \mathrm{~K} \gamma$ inhibition ameliorated imiquimod (IMQ)-induced psoriasis-like dermatitis, correlating with a diminution of skin IL- $17^{+} \gamma \delta$ T cells. Interfering with the $\mathrm{PI} 3 \mathrm{~K} \delta$ and $\mathrm{PI} 3 \mathrm{~K} \gamma$ pathways also inhibited the production of IL-17 and IFN- $\gamma$ by T cells from healthy donors and psoriatic patients, indicating that $\mathrm{PI} 3 \mathrm{~K} \gamma$, together with the $\delta$-isoform, is required for IMQ-induced dermatitis and is a potential target for psoriasis treatment (Roller et al., 2012). Unlike several studies looking into the immunological roles of PI3K $\gamma$ (Barber et al., 2005; Camps et al., 2005; Peng et al., 2010; Rodrigues et al., 2010; Roller et al., 2012), we observed that PI3K $\gamma$ activation in the spinal cord plays an important role during chronic itch.

Sun and Chen (2007) highlighted that GRPR transcript expression is restricted to the laminae I of the mouse spinal cord dorsal horn. Here, we showed that GRP can activate directly (calcium flux) small-size, capsaicin-sensitive DRG neurons via GRPR, an effect that often translates into action potential firing. Our electrophysiological data suggest that GRP injected intrathecally and the consequent scratching behavior might be mediated by central terminals of DRG nociceptive afferent neurons. Such a hypothesis could provide an explanation for the pruritogenic effects of GRP when delivered spinally (Sun and Chen, 2007) and for the recent report of Solorzano et al. (2015) suggesting that spinal interneurons are one of the main sources of GRP in the spinal cord. It is conceivable that interneuron-released GRP could act presynaptically on these DRG afferents. This hypothesis also aligns with a recent report showing that PI $3 \mathrm{~K} \gamma$ is selectively expressed by nociceptive DRG neurons (Leinders et al., 2014). The PI3K $\gamma$ inhibitor that we used here is highly lipophilic and expected to cross the blood-brain barrier (Camps et al., 2005) and has been demonstrated to delay experimental cerebral malaria when given orally (Lacerda-Queiroz et al., 2015). To support a neuronal activity for PI3K $\gamma$, we administered AS605240 systemically and intrathecally and found an equally potent reduction of dry-skin-induced scratching behavior.

Our findings strongly suggest that GRPR is expressed by central terminals of DRG nociceptive afferents, which transmit itch via the PI3K $\gamma /$ Akt pathway. The exact role of $\mathrm{PI} 3 \mathrm{~K} \gamma$ in these 
fibers has yet to be unraveled, but appears to be instrumental for GRPR itch transmission. It is tempting to propose PI3K $\gamma$ as an attractive target with which to control GRPR-mediated pruritus.

\section{References}

Akiyama T, Carstens MI, Carstens E (2010) Enhanced scratching evoked by PAR-2 agonist and 5-HT but not histamine in a mouse model of chronic dry skin itch. Pain 151:378-383. CrossRef Medline

Akiyama T, Tominaga M, Takamori K, Carstens MI, Carstens E (2014) Roles of glutamate, substance $\mathrm{P}$, and gastrin-releasing peptide as spinal neurotransmitters of histaminergic and nonhistaminergic itch. Pain 155: 80-92. CrossRef Medline

Ashwood V, Brownhill V, Higginbottom M, Horwell DC, Hughes J, Lewthwaite RA, McKnight AT, Pinnock RD, Pritchard MC, Suman-Chauhan N, Webb C, Williams SC (1998) PD 176252-the first high affinity nonpeptide gastrin-releasing peptide (BB2) receptor antagonist. Bioorg Med Chem Lett 8:2589-2594. CrossRef Medline

Barber DF, Bartolomé A, Hernandez C, Flores JM, Redondo C, FernandezArias C, Camps M, Rückle T, Schwarz MK, Rodríguez S, Martinez AC, Balomenos D, Rommel C, Carrera AC (2005) PI3Kgamma inhibition blocks glomerulonephritis and extends lifespan in a mouse model of systemic lupus. Nat Med 11:933-935. Medline

Camps M, Rückle T, Ji H, Ardissone V, Rintelen F, Shaw J, Ferrandi C, Chabert C, Gillieron C, Françon B, Martin T, Gretener D, Perrin D, Leroy D, Vitte PA, Hirsch E, Wymann MP, Cirillo R, Schwarz MK, Rommel C (2005) Blockade of PI3Kgamma suppresses joint inflammation and damage in mouse models of rheumatoid arthritis. Nat Med 11:936-943. Medline

Caterina MJ, Leffler A, Malmberg AB, Martin WJ, Trafton J, Petersen-Zeitz KR, Koltzenburg M, Basbaum AI, Julius D (2000) Impaired nociception and pain sensation in mice lacking the capsaicin receptor. Science 288: 306-313. CrossRef Medline

Czepielewski RS, Porto BN, Rizzo LB, Roesler R, Abujamra AL, Pinto LG, Schwartsmann G, Cunha Fde Q, Bonorino C (2012) Gastrin-releasing peptide receptor (GRPR) mediates chemotaxis in neutrophils. Proc Natl Acad Sci U S A 109:547-552. CrossRef Medline

Davidson S, Giesler GJ (2010) The multiple pathways for itch and their interactions with pain. Trends Neurosci 33:550-558. CrossRef Medline

Engelman JA, Luo J, Cantley LC (2006) The evolution of phosphatidylinositol 3-kinases as regulators of growth and metabolism. Nat Rev Genet 7:606-619. Medline

Fougerat A, Gayral S, Gourdy P, Schambourg A, Rückle T, Schwarz MK, Rommel C, Hirsch E, Arnal JF, Salles JP, Perret B, Breton-Douillon M, Wymann MP, Laffargue M (2008) Genetic and pharmacological targeting of phosphoinositide 3-kinase-gamma reduces atherosclerosis and favors plaque stability by modulating inflammatory processes. Circulation 117:1310-1317. CrossRef Medline

Gonzalez N, Moody TW, Igarashi H, Ito T, Jensen RT (2008) Bombesinrelated peptides and their receptors: recent advances in their role in physiology and disease states. Curr Opin Endocrinol Diabetes Obes 15:58-64. CrossRef Medline

Ikoma A, Steinhoff M, Ständer S, Yosipovitch G, Schmelz M (2006) The neurobiology of itch. Nat Rev Neurosci 7:535-547. CrossRef Medline

Inan S, Dun NJ, Cowan A (2011) Investigation of gastrin-releasing peptide as a mediator for $5^{\prime}$-guanidinonaltrindole-induced compulsive scratching in mice. Peptides 32:286-292. CrossRef Medline

Jensen RT, Battey JF, Spindel ER, Benya RV (2008) International Union of Pharmacology. LXVIII. Mammalian bombesin receptors: nomenclature, distribution, pharmacology, signaling, and functions in normal and disease states. Pharmacol Rev 60:1-42. CrossRef Medline

Kardon AP, Polgár E, Hachisuka J, Snyder LM, Cameron D, Savage S, Cai X, Karnup S, Fan CR, Hemenway GM, Bernard CS, Schwartz ES, Nagase H, Schwarzer C, Watanabe M, Furuta T, Kaneko T, Koerber HR, Todd AJ, Ross SE (2014) Dynorphin acts as a neuromodulator to inhibit itch in the dorsal horn of the spinal cord. Neuron 82:573-586. CrossRef Medline

Kini SP, DeLong LK, Veledar E, McKenzie-Brown AM, Schaufele M, Chen SC (2011) The impact of pruritus on quality of life: the skin equivalent of pain. Arch Dermatol 147:1153-1156. CrossRef Medline

Lacerda-Queiroz N, Brant F, Rodrigues DH, Vago JP, Rachid MA, Sousa LP, Teixeira MM, Teixeira AL (2015) Phosphatidylinositol 3-Kinase gamma is required for the development of experimental cerebral malaria. PLoS One 10:e0119633. CrossRef Medline
LaMotte RH, Dong X, Ringkamp M (2014) Sensory neurons and circuits mediating itch. Nat Rev Neurosci 15:19-31. Medline

Lee B, Descalzi G, Baek J, Kim JI, Lee HR, Lee K, Kaang BK, Zhuo M (2011) Genetic enhancement of behavioral itch responses in mice lacking phosphoinositide 3-kinase-gamma (PI3Kgamma). Mol Pain 7:96. CrossRef Medline

Leinders M, Koehrn FJ, Bartok B, Boyle DL, Shubayev V, Kalcheva I, Yu NK, Park J, Kaang BK, Hefferan MP, Firestein GS, Sorkin LS (2014) Differential distribution of PI3K isoforms in spinal cord and dorsal root ganglia: potential roles in acute inflammatory pain. Pain 155:1150-1160. CrossRef Medline

Liu C, Liu TT, He ZG, Shu B, Xiang HB (2014) Inhibition of itch-related responses by selectively ablated serotonergic signals at the rostral ventromedial medulla in mice. Int J Clin Exp Pathol 7:8917-8921. Medline

Liu Q, Tang Z, Surdenikova L, Kim S, Patel KN, Kim A, Ru F, Guan Y, Weng HJ, Geng Y, Undem BJ, Kollarik M, Chen ZF, Anderson DJ, Dong X (2009) Sensory neuron-specific GPCR Mrgprs are itch receptors mediating chloroquine-induced pruritus. Cell 139:1353-1365. CrossRef Medline

Liu XY, Liu ZC, Sun YG, Ross M, Kim S, Tsai FF, Li QF, Jeffry J, Kim JY, Loh HH, Chen ZF (2011) Unidirectional cross-activation of GRPR by MOR1D uncouples itch and analgesia induced by opioids. Cell 147:447458. CrossRef Medline

Maciel IS, Azevedo VM, Pereira TC, Bogo MR, Souza AH, Gomez MV, Campos MM (2014) The spinal inhibition of N-type voltage-gated calcium channels selectively prevents scratching behavior in mice. Neuroscience 277:794-805. CrossRef Medline

Majumdar ID, Weber HC (2011) Biology of mammalian bombesin-like peptides and their receptors. Curr Opin Endocrinol Diabetes Obes 18: 68-74. CrossRef Medline

Merali Z, Bédard T, Andrews N, Davis B, McKnight AT, Gonzalez MI, Pritchard M, Kent P, Anisman H (2006) Bombesin receptors as a novel anti-anxiety therapeutic target: BB1 receptor actions on anxiety through alterations of serotonin activity. J Neurosci 26:10387-10396. CrossRef Medline

Mishra SK, Hoon MA (2013) The cells and circuitry for itch responses in mice. Science 340:968-971. CrossRef Medline

Moody TW, Leyton J, Garcia-Marin L, Jensen RT (2003) Nonpeptide gastrin releasing peptide receptor antagonists inhibit the proliferation of lung cancer cells. Eur J Pharmacol 474:21-29. CrossRef Medline

Passos GF, Figueiredo CP, Prediger RD, Silva KA, Siqueira JM, Duarte FS, Leal PC, Medeiros R, Calixto JB (2010) Involvement of phosphoinositide 3-kinase gamma in the neuro-inflammatory response and cognitive impairments induced by beta-amyloid 1-40 peptide in mice. Brain Behav Immun 24:493-501. CrossRef Medline

Peng XD, Wu XH, Chen LJ, Wang ZL, Hu XH, Song LF, He CM, Luo YF, Chen ZZ, Jin K, Lin HG, Li XL, Wang YS, Wei YQ (2010) Inhibition of phosphoinositide 3-kinase ameliorates dextran sodium sulfate-induced colitis in mice. J Pharmacol Exp Ther 332:46-56. CrossRef Medline

Pereira PJ, Lazarotto LF, Leal PC, Lopes TG, Morrone FB, Campos MM (2011) Inhibition of phosphatidylinositol-3 kinase gamma reduces pruriceptive, inflammatory, and nociceptive responses induced by trypsin in mice. Pain 152:2861-2869. CrossRef Medline

Quintão NL, Passos GF, Medeiros R, Paszcuk AF, Motta FL, Pesquero JB, Campos MM, Calixto JB (2008) Neuropathic pain-like behavior after brachial plexus avulsion in mice: the relevance of kinin B1 and B2 receptors. J Neurosci 28:2856-2863. CrossRef Medline

Rodrigues DH, Vilela MC, Barcelos LS, Pinho V, Teixeira MM, Teixeira AL (2010) Absence of PI3Kgamma leads to increased leukocyte apoptosis and diminished severity of experimental autoimmune encephalomyelitis. J Neuroimmunol 222:90-94. CrossRef Medline

Roller A, Perino A, Dapavo P, Soro E, Okkenhaug K, Hirsch E, Ji H (2012) Blockade of phosphatidylinositol 3-kinase PI3Kdelta or PI3Kgamma reduces IL-17 and ameliorates imiquimod-induced psoriasis-like dermatitis. J Immunol 189:4612-4620. CrossRef Medline

Ross SE (2011) Pain and itch: insights into the neural circuits of aversive somatosensation in health and disease. Curr Opin Neurobiol 21:880887. CrossRef Medline

Shim WS, Tak MH, Lee MH, Kim M, Kim M, Koo JY, Lee CH, Kim M, Oh U (2007) TRPV1 mediates histamine-induced itching via the activation of phospholipase A2 and 12-lipoxygenase. J Neurosci 27:2331-2337. CrossRef Medline 
Solorzano C, Villafuerte D, Meda K, Cevikbas F, Bráz J, Sharif-Naeini R, Juarez-Salinas D, Llewellyn-Smith IJ, Guan Z, Basbaum AI (2015) Primary afferent and spinal cord expression of gastrin-releasing peptide: message, protein, and antibody concerns. J Neurosci 35:648-657. CrossRef Medline

Su PY, Ko MC (2011) The role of central gastrin-releasing peptide and neuromedin $\mathrm{B}$ receptors in the modulation of scratching behavior in rats. J Pharmacol Exp Ther 337:822-829. CrossRef Medline

Sukhtankar DD, Ko MC (2013) Physiological function of gastrin-releasing peptide and neuromedin $\mathrm{B}$ receptors in regulating itch scratching behavior in the spinal cord of mice. PLoS One 8:e67422. CrossRef Medline

Sun YG, Chen ZF (2007) A gastrin-releasing peptide receptor mediates the itch sensation in the spinal cord. Nature 448:700-703. CrossRef Medline
Sun YG, Zhao ZQ, Meng XL, Yin J, Liu XY, Chen ZF (2009) Cellular basis of itch sensation. Science 325:1531-1534. CrossRef Medline

Tattersall M, Cordeaux Y, Charnock-Jones DS, Smith GC (2012) Expression of gastrin-releasing peptide is increased by prolonged stretch of human myometrium, and antagonists of its receptor inhibit contractility. J Physiol 590:2081-2093. CrossRef Medline

Weisshaar E, Dalgard F (2009) Epidemiology of itch: adding to the burden of skin morbidity. Acta Derm Venereol 89:339-350. CrossRef Medline

Wymann MP, Björklöf K, Calvez R, Finan P, Thomast M, Trifilieff A, Barbier M, Altruda F, Hirsch E, Laffargue M (2003) Phosphoinositide 3-kinase gamma: a key modulator in inflammation and allergy. Biochem Soc Trans 31:275-280. CrossRef Medline

Zimmermann M (1983) Ethical guidelines for investigations of experimental pain in conscious animals. Pain 16:109-110. CrossRef Medline 